\title{
Scanning Confocal Microscopy for Study of the Neuromuscular Junction (NMJ) Acethylcholine Receptors(nAChRs): One Model of the Peripheral Nerve Injury Recovered After Fibrin Sealant Use
}

Selma Maria Michelin Matheus ${ }^{1 *}$,Carina Guidi Pinto ${ }^{2}$, Ana Paula Silveira Leite ${ }^{2}$, Arthur Alves Sartor ${ }^{1}$, Felipe Cantore Tibúrcio ${ }^{2}$, Rui Seabra Ferreira Junior ${ }^{3}$, André Luis Filadelpho ${ }^{1}$ and Samara Camaçari de Carvalho $^{4}$

1. Department of Anatomy,São Paulo State University (UNESP), Institute of Biosciences, Botucatu, Brasil.

2. São Paulo State University (UNESP), Medical School, Botucatu, Brasil.

3. São Paulo State University (UNESP), Venoms and Venomous Animals Center, Botucatu, Brasil.

4. University Center Hermínio Ometto Foundation, FHO, Uniararas, Araras, Brasil.

* Corresponding author: selma.matheus@unesp.br

The NMJs are synapses in the peripheral nervous system which transfer information to skeletal muscle fiber. Some techniques are useful for studying NMJs morphology, but they are not ideal for evaluating changes in nAChRs distribution. The laser fluorescence resolution, as seen in confocal microscopy is a good instrument to study the nAChRs remodelations. After denervation obtained by peripheral nerve lesion (PNL) a severe atrophy of the NMJ structure and the associated proteins including the nAChRs takes place [1]. The suture is the gold standard method used after this lesion but the fibrin sealant is an alternative and /or complementary method. The Center for the Study of Venoms and Venomous Animals (CEVAP/Brazil) developed this sealant from the poison of the Crotalus durissus terrificus (rattlesnake) that is innocuous and safe [2]. The focus of this study was to verify the potential of the fibrin sealant associated with a single stitch on the nAChRs of the NMJs after ischiatic nerve lesion using scanning confocal microscopy.

Twenty male adult Wistar rats were utilized (CEUA: 1173/2016), divided into 4 groups: Sham-Control (SC), Denervated-Control (DC), Suture Lesion (SL) and Suture Lesion + Fibrin Sealant (SFS). In SC group only right ischiatic nerve identification was done. In DC, SL and SFS groups fixation of nerve stumps on the musculature after neurotmesis was performed. After 7 days the reconnection of the stumps with suture was realized in SL group and it was associated with the fibrin sealant in SFS group. After sixty days the right soleus muscles were removed and prepared for the morphology analysis by confocal microscopy and after for morphometry of the nAChRs that were labeled with $\alpha$-bungarotoxin conjugated to rhodamine and the nerve terminals were labeled with Anti-neurofilament 200 and FITC. The images were acquired using a Laser Scanning Confocal Microscope (Leica TCS model - SP5) of the $\mathrm{CME} / \mathrm{IBB} /$ Unesp. Measurements were taken from $50 \mathrm{NMJs}$ per animal of each experimental group: motor endplate area, nAChR area, total area of the motor endplate and the largest orthogonal axis of the nAChR. And based on these measurements, relative planar area, mean diameter of NMJ and density of the motor endplate were calculated [3].

The confocal images showed that in SC group, the answers of the fluorophores were homogeneous, with nAChRs marked in autofluorescence and in continuous branches or "pretzel", with intact and preserved nerve terminals. In DC group it was observed flattening of the NMJ, fragmentation of nAChRs, with distribution in "islands" and tangled nerve terminals. In SL and SFS groups, the morphology was inbetween groups SC and DC, with thinner nerve terminals (Figure1). The morphometric data were 
compatible with the morphology and the majority of the parameters of SL and SFS groups presented values in-between SC and DC groups (Table 1). The smaller values were present in DC group. The nerve reconstruction groups (SL and SFS) showed the relative planar area values statistically similar to SC group and higher than DC. It is important to highlight that the higher are the levels of relative planar area the lower will be the fragmentation of nAChRs and vice versa reflecting the index of complexity of the NMJ [3,4]. The confocal microscopy images enabled to study details of the nAChRs remodelations. The high quality of the images allowed to obtain the ideal measurements and it was possible to conclude that the fibrin sealant contributed with the nAChRs of the NMJs recovery in SFS groups [5].

\section{References:}

[1] WA Palispis and R Gupta, Exp. Neurology 290 (2017), p.106.

[2] RS Ferreira, J. of Venomous Animals and Toxins including Tropical Diseases 20 (2014), p. 1.

[3] DC Sieck et al., Respiratory Physiology \& Neurobiology 180 (2012), p. 88.

[4] CNA Pissulin et al., Journal of Photochemistry and Photobiology B: Biology 167 (2017), p. 256.

[5] The authors acknowledge funding from the FAPESP 2017-06472-2.

\begin{tabular}{cccccc}
\hline & SC & DC & SL & SFD & $\begin{array}{c}\text { p } \\
\text { value }\end{array}$ \\
\hline $\begin{array}{c}\text { Area of the } \\
\text { motor endplate } \\
\left(\boldsymbol{\mu m}^{2}\right)\end{array}$ & $635.0 \pm 201.9$ & $400.8 \pm 38.6$ & $559.2 \pm 147.8$ & $427.5 \pm 147.6$ & 0.05 \\
\hline $\begin{array}{c}\text { Area of } \mathbf{n A C h R} \\
\left(\boldsymbol{\mu m}^{2}\right)\end{array}$ & $460.4 \pm 149.1^{\mathrm{a}}$ & $241.4 \pm 31.0^{\mathrm{b}}$ & $362.6 \pm 119.4^{\mathrm{a}, \mathrm{b}}$ & $285.1 \pm 103.2^{\mathrm{a}, \mathrm{b}}$ & 0.02 \\
\hline $\begin{array}{c}\text { Relative } \mathbf{p l a n a r} \\
\text { area }\left(\boldsymbol{\mu m}^{\mathbf{2}}\right)\end{array}$ & $13.3 \pm 2.3^{\mathrm{a}}$ & $7.0 \pm 0.6^{\mathrm{b}}$ & $10.0 \pm 2.1^{\mathrm{a}}$ & $9.4 \pm 1.9^{\mathrm{a}}$ & $<0.01$ \\
\hline $\begin{array}{c}\text { Mean diameter } \\
\text { of NMJ }\left(\boldsymbol{\mu m}^{\mathbf{2}}\right)\end{array}$ & $208.6 \pm 34.7^{\mathrm{a}}$ & $154.0 \pm 9.7^{\mathrm{b}}$ & $183.7 \pm 29.1^{\mathrm{a}, \mathrm{b}}$ & $162.6 \pm 31.8^{\mathrm{a}, \mathrm{b}}$ & 0.02 \\
\hline $\begin{array}{c}\text { Density of the } \\
\text { motor endplate } \\
(\mathbf{\%})\end{array}$ & $73.5 \pm 1.9^{\mathrm{a}}$ & $62.2 \pm 3.7^{\mathrm{b}}$ & $66.4 \pm 8.9^{\mathrm{a}, \mathrm{b}}$ & $67.8 \pm 6.7^{\mathrm{a}, \mathrm{b}}$ & $<0.01$ \\
\hline
\end{tabular}

Table 1. Morphometry analysis of the nAChRs

Values expressed as the mean \pm standard deviation. One Way ANOVA test followed by post-test of multiple comparisons of Tukey. Equal letters for no statistically significant differences $(p>0.05)$ and different letters for statistically significant differences $(\mathrm{p} \leq 0.05)$.
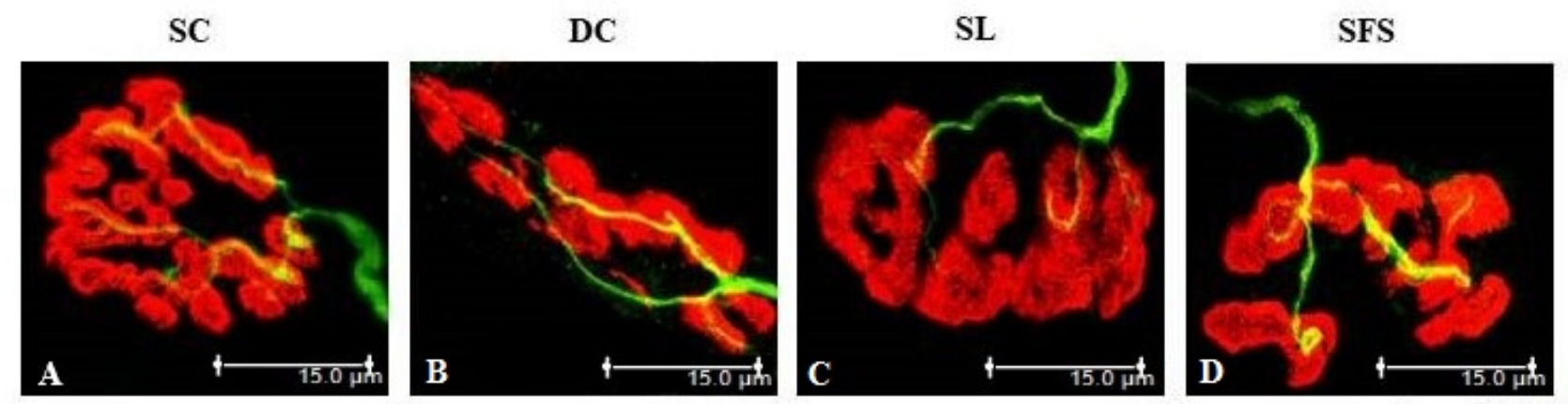

Figure 1. Confocal microscopy of the nAChRs (in red) and nerve terminals (in green). A: SC- Control Sham (SC), B: Control Denervated (DC), C: Suture Lesion (SL) e D: Suture Lesion + Fibrin Sealant (SFS). 